\title{
Projeto Incluir: inclusão digital para pessoas com deficiência
}

\author{
Wender Antônio da Silva ${ }^{1}$, Ornélio Hinterholz Jr. ${ }^{2}$, Ângelo Augusto Costa Freire ${ }^{3}$,
Gracieth Mendes Valenzuela \\ ${ }^{1,2,3,4}$ Professor do Curso de Licenciatura em Computação da Estacio Atual - Faculdade \\ Estácio da Amazônia, Boa Vista, RR - Brasil. \\ \{wender.silva, ornelio.junior, gracieth.mendes, angelo.freire\}@estacio.br
}

\begin{abstract}
This paper describes a project for digital inclusion for people with special needs in the city of Boa Vista, Roraima. This project aims to bring basic computer knowledge that these people are included digitally and socially, and even lead notions citizenship and autonomy for people at risk, finally makes $A$ research on the evolution of these persons to have contact with computing.
\end{abstract}

Resumo. Este trabalho descreve um projeto de inclusão digital para pessoas com necessidades especiais realizado na cidade de Boa Vista, estado de Roraima. Este projeto visa levar conhecimentos básicos de informática para que estas pessoas sejam incluidas digitalmente e socialmente, e ainda, levar noções de cidadania e de autonomia para pessoas em situação de risco e, por fim fez-se pesquisa sobre a evolução em aspectos sociais e profissionais destas pessoas ao terem contato com a informática.

\section{Introdução}

Este trabalho visa descrever as ações de Responsabilidade Social que são realizadas na Estácio Atual - Faculdade Estácio da Amazônia que possuem como objetivo para a IES formar profissionais socialmente responsáveis e, ainda de estar atuando amplamente na vida social onde a mesma está inserida. No decorrer dos anos de sua existência no bairro União, as mudanças foram sentidas nos aspectos urbanísticos, econômicos e sociais. Assim, nasce o Projeto Incluir, o qual visa oferecer gratuitamente cursos de Informática Básica para portadores de necessidades especiais da cidade de Boa Vista, no estado de Roraima.

\section{O Projeto Incluir}

A situação das Pessoas com Necessidades Especiais (PNE) quanto à falta de oportunidades de trabalho e quanto à situação de risco socioeconômico e que vivem. É nesta classe social menos favorecida, onde praticamente não existem pessoas qualificadas para o mercado de trabalho. Desta forma as PNEs se veem forçadas à mendicância ou a inatividade, e ainda pior como mão-de-obra barata e desqualificada. $\mathrm{O}$ referido artigo descreve o projeto Incluir que, nasce da necessidade de enfrentar a problemática da falta de qualificação profissional, da geração de renda e de um local de referência para a pessoa com deficiência, realizando assim a integração da pessoa com deficiência conforme a Lei ${ }^{\circ} .3298$ de 20/12/1999, art. $n^{\circ} .31,32$, 33 e o art. $n^{\circ} .34 ; \S 1^{\text {o }}$ - I; $\S 4^{\circ}$. Sabe-se que no Brasil, o principal motivo que contribui para a falta de mão-deobra de deficientes é a baixa qualificação. Apesar da falta de estatísticas confiáveis, sabe-se que a média de escolaridade desse grupo é ainda menor que a já baixíssima média nacional, de seis anos de estudo.

O avanço social da maior parte dos deficientes no Brasil é limitado pela baixa renda, acesso muito limitado à cultura formal e políticas públicas inadequadas ao seu 
desenvolvimento social. Esse imenso contingente encontra-se, em sua maioria, fora do mercado de trabalho por falta de capacitação profissional. Um dos fatores que levam a este cenário é a ausência de uma política de incentivo a programas de capacitação de deficientes por parte das Instituições Públicas e Privadas. Neste sentido o Projeto Incluir tem como objetivo intervir nas questões sociais $\mathrm{e}$ apoiar $\mathrm{o}$ crescimento $\mathrm{e}$ a independência pessoal das pessoas portadoras de deficiência, que vem sofrendo discriminações devido à falta de entendimento da sociedade sobre suas necessidades e potencialidades.

\section{Metodologia de Trabalho para o Projeto Incluir}

O artigo é baseado na descrição do Projeto Incluir e de como o mesmo foi e está sendo implementado. Para a realização do treinamento foram disponibilizados os laboratórios de informática e salas de aula da Estácio Atual. As turmas são divididas de acordo com suas necessidades e habilidades cabendo aos acadêmicos do curso de Licenciatura em Computação a monitoria das aulas assistidas por um professor orientador e assessoradas por alunos do curso de Serviço Social. Todos os Módulos possuem material didático, sendo este material elaborado pelos professores e monitores dos módulos. As aulas são realizadas aos sábados nas dependências da IES. Os cursos oferecidos são voltados para a capacitação profissional deste público, ou seja, curso de Informática Básica com Software Livre. Toda a capacitação possui uma carga horária de 60 horas, incluindo palestras com representante do Ministério Público Federal, Psicólogos e Assistentes Sociais.

\section{Articulação do projeto com o Ensino, Pesquisa, Extensão e as demandas sociais.}

A proposta do projeto traz intrinsecamente variantes que demonstram o alto relacionamento entre ensino e pesquisa. A capacitação dos envolvidos nos módulos de informática gera essa articulação, já que podemos investigar os sujeitos da pesquisa antes e depois da implementação do projeto. O Projeto Incluir é parte de um processo de Inclusão Digital e Social, desta forma é um ótimo objeto de estudo para os alunos dos cursos de Licenciatura em Computação e, é uma oportunidade ímpar para realizar as práticas pedagógicas, sendo os mesmos, observadores de todo o processo realizado.

\section{Atividades e pesquisas já realizadas}

As atividades do Projeto Incluir proporcionam a capacitação em conhecimentos básicos de informática, com curso de carga horária de 60 horas, divididas em 04 horas semanais realizadas aos sábados de 08:00 as 12:00 horas em 02 laboratórios de informática da Estácio Atual - Faculdade Estácio da Amazônia, tendo como beneficiários, no primeiro momento, 24 pessoas com necessidades especiais vinculados a Associação dos Deficientes Físicos de Roraima (ADF/RR), compondo 02 turmas de 12 alunos cada. Além disso, foram realizadas palestras sobre Noções de Cidadania, Legislação Trabalhista e de cunho motivacional. As atividades desenvolvidas no $2^{\circ}$ semestre de 2011 tiveram como objetivo nivelar os conhecimentos e propor um aprendizado básico a respeito de sistemas operacionais e ferramentas de escritório, assim como abrir um espaço para discussão em sala de aula sobre o mercado de trabalho e seus princípios éticos e constitucionais para com os portadores de deficiência. Ressalta-se que o projeto continua em operação, porém ainda não foram levantados os dados de 2012.2. 


\section{Análise do Projeto Incluir}

Um dos fatores de sucesso das atividades desenvolvidas no Projeto Incluir é a formação de um relacionamento sólido onde predominam relações de confiança e responsabilidade para com o trabalho social. Desta forma, destacam-se alguns dos resultados já alcançados: - Inserção dos beneficiários no mercado de trabalho, após o início do Projeto; - Conforme observado pelos monitores e orientadores houve evolução no conhecimento inicial da informática, proporcionando a inclusão no mundo digital; - Melhora no rendimento escolar em 70\% dos beneficiários, pois se constata interesse em preparar trabalhos escolares utilizando-se das vantagens oferecidas pelo computador; - Melhora no convívio social e na autoestima de todos envolvidos; - Cerca de $90 \%$ dos beneficiários despertaram interesse em relação aos direitos e deveres como cidadão; - Promoção do voluntariado, haja vista que os monitores do Projeto são todos voluntários e, Ampliação das práticas de inclusão digital no estado de Roraima;

\subsection{Análise dos dados}

Ao final dos cursos ministrados no Projeto Incluir foi realizada uma pesquisa com os beneficiários onde teve-se a intenção de verificar o grau de satisfação dos mesmos para com o andamento do Projeto.

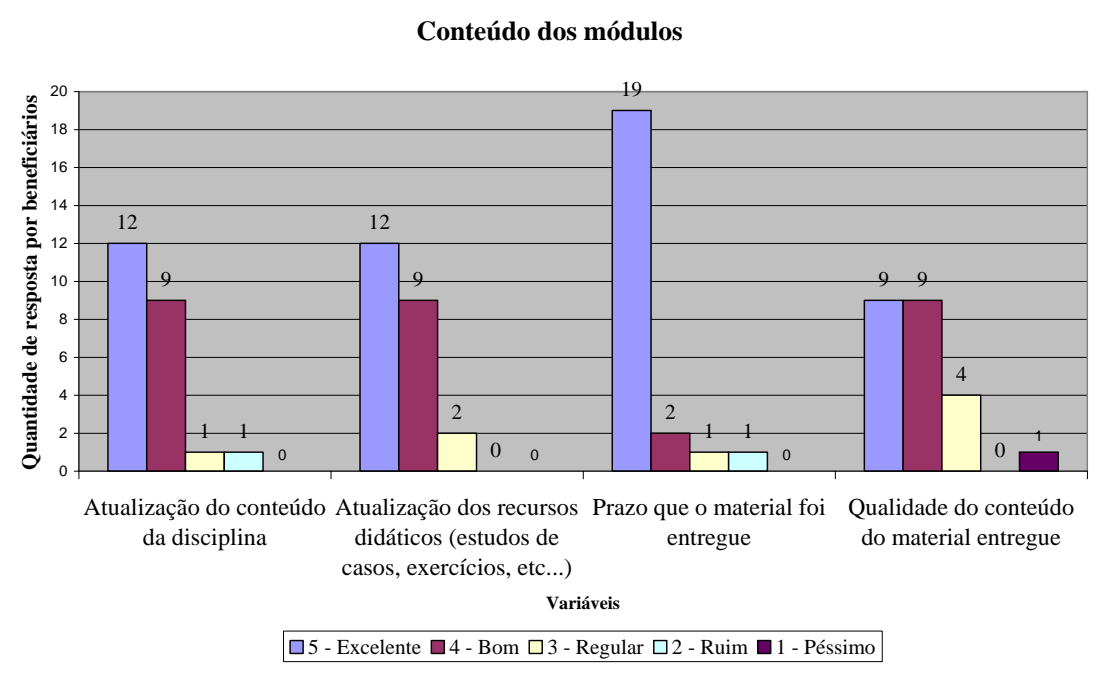

Gráfico 01: Avaliação do conteúdo das disciplinas - material didático.

Do ponto de vista da maioria dos beneficiados do Projeto, o conteúdo das disciplinas está com ótima atualização. Os recursos didáticos estão atendendo as expectativas, resultando em excelente nível de satisfação, sendo entregue em tempo hábil (dentro do estabelecido em cada módulo). O Gráfico 01 demonstra os dados obtidos em relação ao questionário que trata da avaliação do conteúdo das disciplinas, e os materiais didáticos aplicados aos alunos. $\mathrm{O}$ resultado alcançado foi viável devido à orientação pedagógica da coordenação do Curso de Licenciatura em Computação, Coordenação de Extensão e Núcleo de Apoio ao Estudante juntamente com o esforço dos monitores na busca de conhecimento dos conteúdos trabalhados, resultando em um material atualizado e com conteúdo significante.

Da avaliação dos monitores pelos PNE participantes do Projeto Incluir, resultou em um excelente nível de satisfação. O gráfico 02 ilustra as variáveis analisadas: 
Avaliação dos monitores

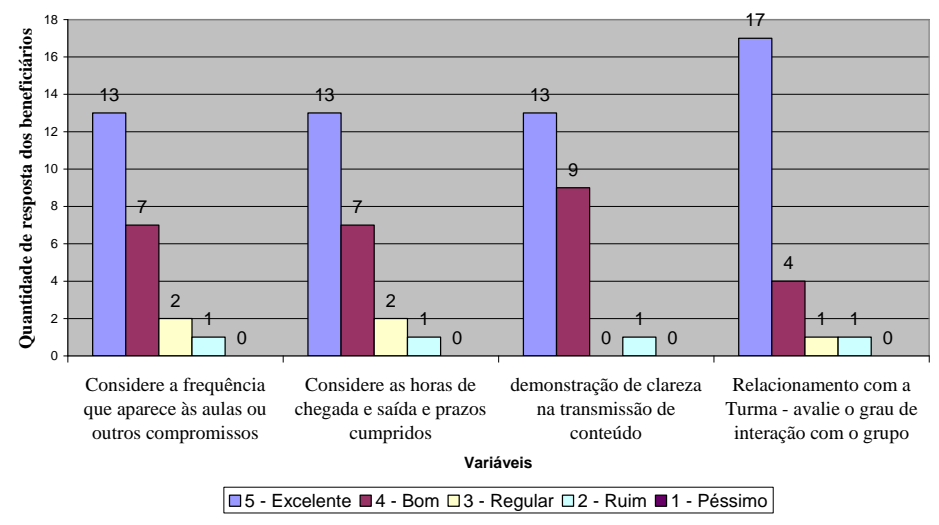

Gráfico 02: Avaliação da atuação dos monitores do Projeto Incluir.

O gráfico 02 reflete, de forma indireta, que os monitores voluntários são capacitados para atuarem em projetos com essa envergadura. Por tratar-se de um projeto que tem como público alvo os PNE, a estrutura física do local, onde as atividades são desenvolvidas, deve ser levada em consideração. Desta forma, é proposta a avaliação do local físico (IES) que obteve um resultado satisfatório, conforme visualização dos dados exposta no gráfico 03 .

Local de realização do curso - estrutura física

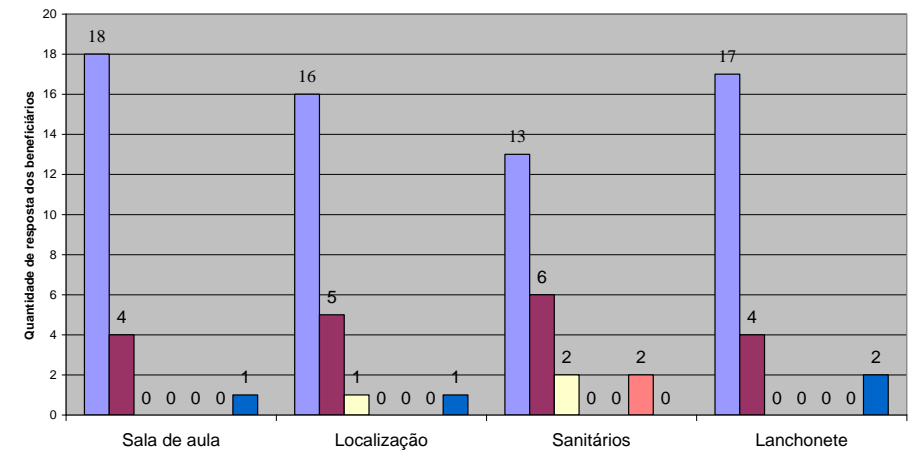

$\square 5$ - Excelente $\square 4$ - Bom $\square 3$ - Regular $\square 2$ - Ruim $\square 1$ - Péssimo $\square$ NA - Não se Aplica $\square$ Resposta em branco

\section{Gráfico 03: Avaliação de alguns pontos da estrutura física da IES}

Visando entender os resultados alcançados na visão dos beneficiados do projeto, em relação aos conhecimentos de informática, observa-se que já houve melhoras no aprendizado básico de informática, os resultados estão ilustrados no Gráfico 04.

Avaliação pessoal - Conhecimento em informática

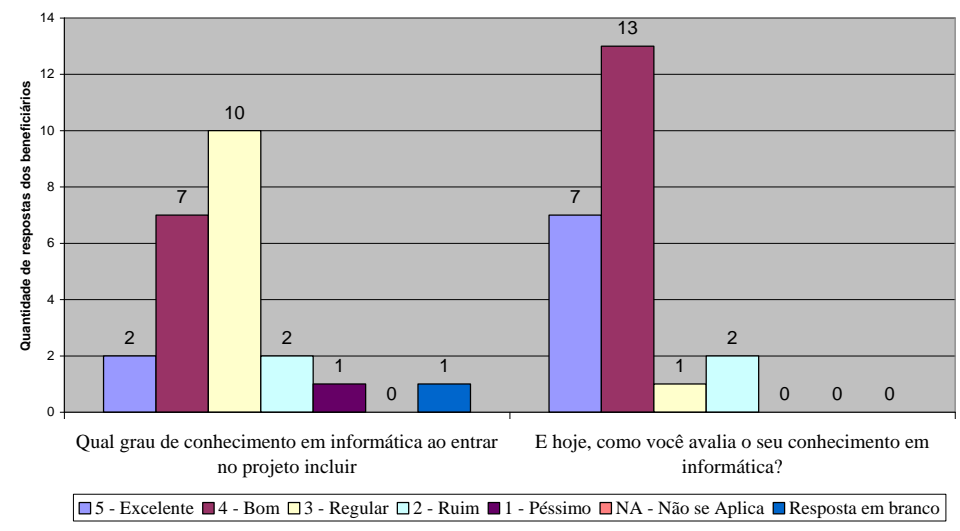

Gráfico 04: Comparativo do conhecimento adquirido antes e durante o Projeto Incluir 
Como um dos objetivos do projeto é a capacitação para a inserção no mercado de trabalho, o gráfico 05 ilustra que o percentual de $48 \%$ dos entrevistados estava fora do mercado de trabalho.

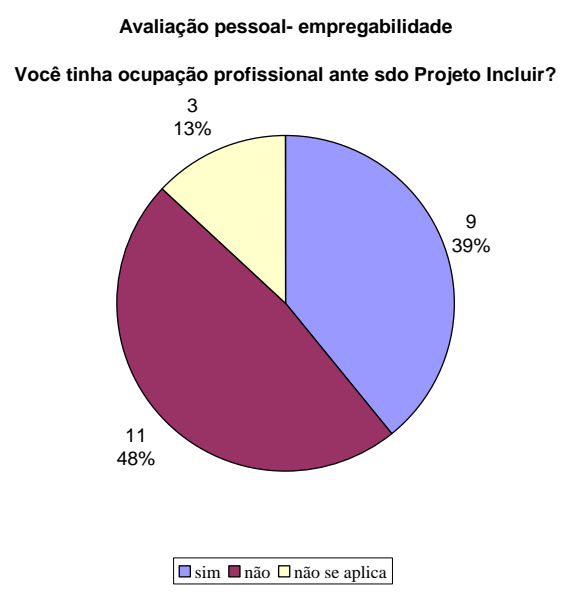

\section{Gráfico 05: Percentual de beneficiados empregados antes de iniciarem no Projeto Incluir}

Dos que afirmaram já ter ocupação antes do projeto, 100\% responderam que o conhecimento adquirido no decorrer das aulas do projeto contribuiu na melhora do desempenho. Sobre a influência da participação no Projeto Incluir, 100\% responderam que contribui muito na vida pessoal.

\section{Considerações Finais}

Por meio deste projeto e desta pesquisa, constatou-se que as pessoas com necessidades especiais possuem grande potencial para atuarem no mercado de trabalho. A discriminação e o preconceito fazem com estas pessoas fiquem acorrentadas a um medo de não serem produtivas. Os resultados obtidos com a inserção digital e social destas pessoas foi enorme, visto que boa parte dos alunos estão empregados ou deram continuidade aos estudos. Em relação a viabilidade de projetos e pesquisas como estas, os gráficos deixam claro que é necessário investimento para que se tenha uma sociedade igualitária.

\section{Referências}

Vallayes, François. “Que significa responsabilidade social universitária?” Estudos. Ano 24. No 36. Junho: 2006.

De La Jara. "Responsabilidade Social Universitária: uma experiência inovadora na América Latina". Estudos. Ano 24. №36. Junho: 2006.

Brasil. Lei federal $n^{\circ} .8213 / 9$. DataPrev. Julho de 2010. Acesso:

http://www3.dataprev.gov.br.

Brasil. Lei federal no 3298 de 20/12/1999. DataPrev. Julho de 2010. Acesso: http://www3.dataprev.gov.br.

ONU/Brasil. "Estatísticas Brasileiras". Organização das Nações Unidas. Julho de 2010. Acesso: http://www.onu-brasil.org.br/.

IBGE. "Instituto Brasileiro de Geografia e Estatística”. Acesso: Janeiro de 2007.

FBB. "Retratos da Deficiência no Brasil". Fundação Banco do Brasil/Getúlio Vargas. Julho de 2010. Acesso: http://www.fbb.org.br 